\title{
A METHOD FOR MEASURING OXYGEN CONSUMPTION AND CARDIAC OUTPUT IN INTENSIVE CARE UNITS
}

\author{
John L. Hoyt AND Azmy R. Boutros
}

Cardiac output ( $\mathrm{CO}$ ) is an important variable in assessing cardiovascular function in seriously ill or injured patients in Intensive Care Units (ICU).

The purpose of this study was to assess the reproducibility of a simplified method of measuring oxygen consumption $\left(\mathrm{V}_{\mathrm{O}_{2}}\right)$, arterio-mixed venous oxygen difference $\left(\mathrm{Ca}_{\mathrm{O}_{2}}-\mathrm{Cv}_{\mathrm{O}_{2}}\right)$ measurements and subsequent $\mathrm{CO}$ calculations using the Fick principle, under clinical conditions encountered in the ICU.

\section{METHOD}

All subjects were patients who underwent open-heart surgery with cardiopulmonary bypass. All patients had indwelling brachial or radial arterial catheters (18-gauge Longdwel teflon catheters) placed before induction of anaesthesia, and an 8-inch vinyl tubing (B.D. \#6129) placed in the pulmonary artery (PA) and passed through the chest wall before closure of the sternotomy.

Twenty-six patients were studied. All patients were subjected to three consecutive sets of measurements several minutes apart. None of the patients was receiving vasoactive drugs and no sedatives or other medications were given immediately before the first measurement or between subsequent measurements.

Intravenous fluids were run at approximately 15 drops per minute during the measurements to minimize deviations from steady state. Blood loss from the chest tubes was minimal and systemic blood pressure variations were less than \pm 10 per cent during the measurements. No air leakage out of the chest tubes was present in any patient at the time measurements were made. Patients were divided into two groups.

Group 1: Spontaneously ventilating patients:

$\mathrm{V}_{\mathrm{O}_{2}}$ and $\mathrm{Ca}_{\mathrm{O}_{2}}-\mathrm{Cv}_{\mathrm{O}_{2}}$ were measured on the first postoperative day in ICU, and $\mathrm{CO}$ was calculated in 15 patients.

$V_{O_{2}}$ measurement: Patients breathed spontaneously through a tracheal tube or a mouthpiece into a Godart Pulmonet type 114 (Figure 1A). The spirometer bell was filled with oxygen. The system was left for five minutes before attaching it to the patient to allow time for oxygen in solution in the water under the bell to reach equilibrium with oxygen in the gas phase. Carbon dioxide in exhaled gas was removed by a soda lime absorber on the expired limb. The depression of the bell, measured by the recorded slope, represented $\mathrm{C}_{\mathrm{O}_{2}}$. Inspired oxygen concentration between measurements was kept constant in each patient $\left(\mathrm{F}_{\mathrm{I}_{2}} 0.5-0.6\right)$.

From the Department of Anesthesiology and Intensive Care Unit, University of Iowa Hospitals, Iowa City, Iowa 52242. 


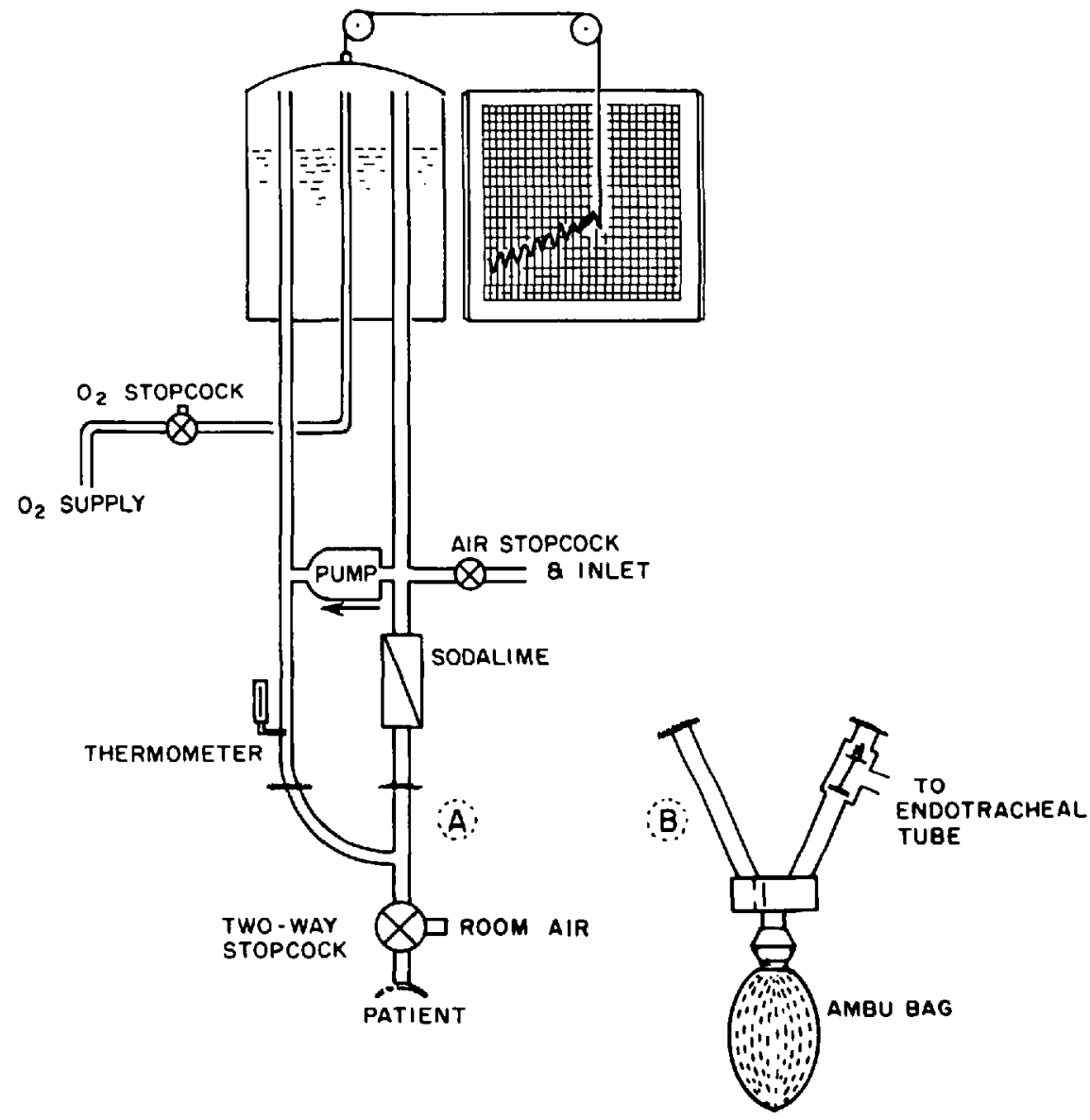

Figure 1. Schematic representation of the Godart Pulmonet. A: for patients ventilating spontaneously. B: a modification for manually ventilating lungs of apnoeic patients, using two unidirectional valves.

Temperature of the spirometer gas was noted and the volume was corrected to STPD.

Arterio-venous oxygen difference measurement: Duplicate arterial and pulmonary artery blood samples were simultaneously collected during the second minute of the three-minute period of measurement of $\mathrm{V}_{\mathrm{O}_{2}}$. Blood was drawn in heparinized pre-iced $5 \mathrm{ml}$ glass syringes. Blood samples were processed within 5-10 minutes.

The following variables were measured: arterial and mixed venous haemoglobin ( $\mathrm{Hba}$ and $\mathrm{Hb} \overline{\mathrm{v}}$ respectively) and arterial and mixed venous oxygen saturation ( $\mathrm{Sa}_{\mathrm{O}_{2}}$ and $\mathrm{S}_{\mathrm{O}_{2}}$ respectively) using IL Co-oximeter model $182^{\circ}$ frequently calibrated. Arterial and mixed venous oxygen tensions $\left(\mathrm{Pa}_{\mathrm{O}_{2}}\right.$ and $\mathrm{P}_{\mathrm{O}_{2}}$ respectively) were measured using the IL 313 gas analyzer* which was recalibrated before every measurement.

'Instrument Laboratory Inc., Lexington, Massachusetts 02173. 
Cardiac output was calculated from the following formula:

$$
\text { CO liter } / \text { minute }=\quad \frac{\mathrm{V}_{\mathrm{O}_{2}}(\mathrm{STPD})}{\left(\mathrm{Ca}_{\mathrm{O}_{2}}-\mathrm{C} \nabla_{\mathrm{O}_{2}}\right) \times 10}
$$

where:

$$
\begin{aligned}
& \mathrm{Ca}_{\mathrm{O}_{2}}=\left(\mathrm{Hba} \times 1.38 \times \mathrm{Sa}_{\mathrm{O}_{2}}\right)+\left(\mathrm{Pa}_{\mathrm{O}_{2}} \times 0.0031\right) \\
& \mathrm{Cv}_{\mathrm{O}_{2}}=\left(\mathrm{Hb} \overline{\mathrm{v}} \times 1.38 \times \mathrm{S}_{\mathrm{O}_{2}}\right)+\left(\mathrm{P}_{\mathrm{O}_{2}} \times 0.0031\right)
\end{aligned}
$$

Group 2: Apnoeic patients: Only $\mathrm{V}_{\mathrm{O}_{2}}$ was measured in 11 patients in the immediate postoperative period. Patients were in the recovery room, curarized and apnoeic. The same criteria of steady state were applied as in group 1. The Godart spirometer system was modified by the inclusion of two unidirectional valves and a self-inflating Ambu bag (Figure 1B) to permit positive pressure ventilation without disrupting the bell of the spirometer and at the same time maintain the system fully closed. The blower in the Pulmonet System must be turned off.

Reproducibility of results in each set of three measurements on each patient was expressed as a coefficient of variation. Student $t$ test was used for statistical analysis of results. ${ }^{1}$

\section{Results}

There were no significant differences between $\mathrm{Pa}_{\mathrm{O}_{2}}$ and $\mathrm{Pa}_{\mathrm{CO}_{2}}$ values obtained in the three measurements in each patient. Tidal volumes and minute ventilations remained fairly constant in all three measurements. Oxygen consumption values are shown in Tables $I$ and II. Coefficients of variation for $V_{\mathrm{O}_{2}}$ were \pm 3.16 per cent and \pm 3.42 per cent in groups 1 and 2 respectively.

Results of $\left(\mathrm{Ca}_{\mathrm{O}_{2}}-\mathrm{C}_{\mathrm{O}_{2}}\right)$ measurement and $\mathrm{CO}$ calculations are shown in Table III with coefficients of variation of \pm 4.63 per cent and \pm 4.70 per cent respectively.

There was no statistically significant difference between values for $\mathrm{Hba}$ and $\mathrm{Hb} \bar{v}$ as measured in this study.

Cardiac output and $\mathrm{Ca}_{\mathrm{O}_{2}}-\mathrm{C}_{\mathrm{O}_{2}}$ figures obtained by using same values for $\mathrm{Hb} \bar{v}$ as for Hba were not statistically different from figures shown in Table III. However coefficients of variation were \pm 3.27 per cent for $\mathrm{CO}$ and \pm 3.39 per cent for $\mathrm{Ca}_{\mathrm{O}}-\mathrm{C}_{\mathrm{v}_{2}}$.

\section{Discussion}

The validity of the Fick method for CO measurements has been established.2.3 Comparison of the direct Fick method with dye dilution and thermal dilution methods for $\mathrm{CO}$ measurements have shown insignificant differences as reported by most investigators, ${ }^{4,5,6}$ although large discrepancies have been reported ${ }^{7}$ and the source of such errors analyzed. ${ }^{8}$

In this study we simplified the method of measurement of $V_{0_{2}}$ on controlled or spontaneous ventilation. Sources of error in measuring oxygen consumption such as removal of some of the oxygen from the system by solution in water, by equilibration with alveolar oxygen concentrations or by leakage from bronchopleural communications were essentially eliminated. Oxygen could have been "lost" to the system if the functional residual capacity (F.R.C.) was allowed to 
TABLE I

$\dot{\mathrm{V}}_{\mathrm{O}_{2}}$ (STPD) SPONTANEOUSLY Ventilating Patients (Group 1)

\begin{tabular}{clll}
\hline \hline Patient & \multicolumn{1}{c}{1} & \multicolumn{1}{c}{2} & \multicolumn{1}{c}{3} \\
\hline 1 & 290 & 285.5 & 280 \\
2 & 234 & 228 & 228.5 \\
3 & 179.5 & 186.5 & 191.5 \\
4 & 256 & 249 & 249 \\
5 & 257 & 259 & 256 \\
6 & 367 & 356.5 & 348 \\
7 & 305 & 281 & 282.5 \\
8 & 213.5 & 224 & 194 \\
9 & 276.5 & 281.5 & 276 \\
10 & 350 & 347.5 & 356.5 \\
11 & 214 & 212 & 215 \\
12 & 168 & 158 & 150 \\
13 & 247 & 228 & 250 \\
14 & 195 & 190 & 189 \\
15 & 235 & 241.5 & 225 \\
\hline
\end{tabular}

Mean value \pm S.D. $=249 \mathrm{ml} \pm 7.88 \mathrm{ml}$.

TABLE II

$\dot{\mathrm{V}}_{\mathrm{O}}$ (STPD) in ApNoeic Patients (GROUP 2)

\begin{tabular}{cccc}
\hline \hline Patient & 1 & 2 & 3 \\
\hline 1 & 315 & 322 & 326 \\
2 & 226 & 241 & 230 \\
3 & 238 & 234 & 236 \\
4 & 346 & 349 & 341 \\
5 & 178 & 189 & 194 \\
6 & 300 & 285 & 291 \\
7 & 176 & 172 & 182.5 \\
8 & 172 & 184 & 182.5 \\
9 & 246 & 213 & 218 \\
10 & 203 & 211 & 213.5 \\
11 & 178 & 191 & 198 \\
\hline \multicolumn{4}{l}{ Mean value \pm S.D.: $235.36 \mathrm{ml} \pm 8.06}$.
\end{tabular}

increase and the reverse if F.R.C. were to become smaller. However, it is unlikely that a system that produced zero end-expired pressures would lead to variable increase in F.R.C. Stability of arterial blood gas values and tidal volumes were perhaps reasonable indications of the stability of F.R.C. A method utilizing more elaborate equipment for continuous $V_{\mathrm{O}_{2}}$ measurements has previously been described by Engström with the use of the Engström respirator. ${ }^{0}$ The need for collecting mixed expired gas for 10 minutes as recommended by Stern $^{10}$ was eliminated. The actual time needed for measuring $\mathrm{V}_{\mathrm{O}_{2}}$ was four minutes.

Though we utilized the conveniently placed PA catheter for obtaining mixed venous blood in this study and in open-heart patients, the present method of using a properly placed Swan-Ganz for collecting mixed venous blood in other ICU patients is no different. 
TABLE III

Cardiac Output and Arterio-Venous Oxygen Difference in Patients in Group 1

\begin{tabular}{|c|c|c|c|c|c|c|}
\hline \multirow[b]{2}{*}{ Patient } & \multicolumn{3}{|c|}{$\mathrm{CO} \mathrm{L} / \mathrm{min}$} & \multicolumn{3}{|c|}{$\mathrm{CaO}_{2}-\mathrm{Cv}_{2} \mathrm{ml} / 100 \mathrm{ml}$} \\
\hline & 1 & 2 & 3 & 1 & 2 & 3 \\
\hline 1 & 5.49 & 5.60 & 5.14 & 5.29 & 5.10 & 5.45 \\
\hline 2 & 5.12 & 5.21 & 5.39 & 4.58 & 4.38 & 4.24 \\
\hline 3 & 3.10 & 2.98 & 3.10 & 5.79 & 6.25 & 6.17 \\
\hline 4 & 4.93 & 5.11 & 5.41 & 5.20 & 4.88 & 4.61 \\
\hline 5 & 4.89 & 4.70 & 4.60 & 5.27 & 5.52 & 5.56 \\
\hline 6 & 7.45 & 8.09 & 8.07 & 4.93 & 4.41 & 4.31 \\
\hline 7 & 5.23 & 4.92 & 4.97 & 5.83 & 5.71 & 5.68 \\
\hline 8 & 2.65 & 3.04 & 2.81 & 8.07 & 7.39 & 6.92 \\
\hline 9 & 5.01 & 5.02 & 4.90 & 5.52 & 5.60 & 5.64 \\
\hline 10 & 5.16 & 5.67 & 5.68 & 6.78 & 6.13 & 6.28 \\
\hline 11 & 3.81 & 3.64 & 3.28 & 5.61 & 5.81 & 6.55 \\
\hline 12 & 2.06 & 2.12 & 2.07 & 8.14 & 7.46 & 7.25 \\
\hline 13 & 3.34 & 3.04 & 3.42 & 7.37 & 7.49 & 7.32 \\
\hline 14 & 1. 31 & 1.22 & 1.25 & 14.88 & 15.63 & 15.11 \\
\hline 15 & 2.96 & 3.13 & 2.87 & 7.91 & 7.72 & 7.82 \\
\hline $\begin{array}{l}\text { Mean } \\
\text { S.D. }\end{array}$ & 1 & & & & & \\
\hline
\end{tabular}

\section{SUMMARY}

A simplified measurement of oxygen consumption was investigated in 15 spontaneously ventilating and 11 apnoeic patients in the intensive care unit following open-heart surgery, using a Godart Pulmonet type 1le. Three consecutive measurements were performed on each patient to define the reproducibility of the method. The coefficient of variation of $V_{0_{2}}$ was \pm 3.16 per cent and \pm 3.42 per cent in spontaneously breathing and apnoeic patients respectively. Arteriomixed venous oxygen difference $\left(\mathrm{Ca}_{0_{2}}-\mathrm{Cv}_{\mathrm{O}_{2}}\right)$ was also measured and cardiac output ( $\mathrm{CO}$ ) calculated using the Fick principle, in the spontaneously ventilating patients. Coefficient of variation of $\mathrm{Ca}_{\mathrm{O}_{2}}-\mathrm{Cv}_{\mathrm{O}_{2}}$ and $\mathrm{CO}$ values were \pm 4.63 per cent and \pm 4.70 per cent respecetively.

\section{RÉSUMÉ}

Les auteurs ont fait l'évaluation d'une méthode simple permettant d'établir la consommation d'oxygène $\left(\mathrm{V}_{\mathrm{O}_{2}}\right)$ au moyen d'un appareil Pulmonet de Godart de type 114. Ces mesures ont été effectuées dans l'unité de soins intensifs, après chirurgie cardiaque, chez quinze malades en respiration spontanée et chez onze autres curarisés et apnéiques. On a repris la procédure à trois reprises chez chaque malade afin d'établir la marge de variation de la méthode. Le coefficient de variation a été respectivement de \pm 3.16 et de \pm 3.42 pour cent chez les malades en respiration spontanée et chez ceux en apnée.

On a également fait la mesure de la différence artério-veineuse $\left(\mathrm{Ca}_{\mathrm{O}_{2}}-\mathrm{Cv}_{\mathrm{O}_{2}}\right)$ et ainsi on a pu calculer le débit cardiaque selon le principe de Fick chez les malades en respiration spontanée. 
Les coefficients de variations de la différence artério-veineuse centrale $\left(\mathrm{Ca}_{\mathrm{O}_{2}}-\right.$ $\mathrm{Cv}_{\mathrm{O}_{2}}$ ) et ceux du débit cardiaque s'établissaient respectivement à \pm 4.63 et \pm 4.7 pour cent.

\section{REFERENCES}

1. Huntsberger, D.V. \& Leaverton, P.E. Statistical inference in the biomedical sciences. Boston, Allyn and Bacon (1970) page 29.

2. Thomasson, B. Cardiac output in normal subjects under standard basal conditions. The repeatability of measurements by the Fick method. Scand. J. Clin. \& Lab. Investigation 9: 365 (1957).

3. SeEty, R.D., NerLuk, W.E., \& GregG, D.E. The comparison of cardiac output determined by the Fick procedure and a direct method using the rotameter. Circulation 1 : 1261 ( 1950$)$.

4. Grevrk, A. Errors of the dye dilution method compared to the direct Fick method in determination of cardiac output in man. Scand. J. Clin. \& Lab. Investigation 18: 486 (1966).

5. Enghoff, E., Michaelsson, M., Pavek, U., \& SJogren, S.A. A comparison between the thermal dilation method and the direct Fick and the dye dilution methods for cardiac output measurements in man. Acta. Soc. Med. 75: 157 (1970).

6. Branthwarte, M.A. \& Bradeey, R.D. Measurement of cardiac output by thermal dilution in man. J. Appl. Physiol. 24: 434 (1968).

7. MAKos, G.G., HADDY, F.J., \& Visscher, M.B. Discrepancies of cardiac output measured by two applications of the direct Fick principle. Am. J. Physiology 117: 752 (1952).

8. Visscher, M.D., Johnson, J.A. The Fick principle: analysis of potential errors in its conventional application. J. Appl. Physiology 5: 635 (1953).

9. Encstrom, C.G., Herzog, P., \& Norlander, O. A method for the continuous measurement of oxygen consumption in the presence of inert gases during controlled ventilation. Acta Anaesth. Scandinav. 5: 115 (1961).

10. Stern, B. \& Strom, G. Errors and differences of method in determination of basal oxygen uptake. Nord Med. 7: 243 (1957). 